\title{
[. Radiological Evaluation of Pregnancy Associated Breast Carcinoma: A Retrospective Study
}

AAKRITI KAPOOR 1 , ANJUM SYED 2 , BINA RAVI ${ }^{3}$, SHALINEE RAO 4 , MANOJ GUPTA ${ }^{5}$,

SURABHI MEHROTRA', DIVYA PANDEY', PRIYANKA GUPTA ${ }^{8}$

\section{ABSTRACT}

Introduction: Pregnancy-Associated Breast Cancer (PABC) is any breast cancer diagnosed during pregnancy or within 12 months after delivery. PABC is a rare, having an incidence of approximately $0.3 / 1000$ pregnancies, however it's incidence is increasing as more and more women are delaying childbearing.

Aim: To evaluate the radiological features of pregnancy associated carcinoma and spread awareness of this entity, as knowledge of PABC will help in its early diagnosis and decrease mortality.

Materials and Methods: This retrospective study was conducted in Integrated Breast Care Centre (IBCC) in All India Institute of Medical Sciences, Rishikesh, from $1^{\text {st }}$ January 2019 to $30^{\text {th }}$ June 2019. Pre designed proforma was used to collect all relevant information, which included patient data, clinical and examination finding and provisional diagnosis. Brief history regarding any risk factors was taken. All pregnant/lactating patients who presented with breast lump were evaluated by Ultrasonography (USG) and/or mammography and appropriate BIRADS was assigned. In selected patients CEMRI breasts was also done. The histopathologically proven malignant lesions were included in the study.

Results: From $1^{\text {st }}$ January 2019 to $30^{\text {th }}$ June 2019 , 196 cases of carcinoma breast came to IBCC, out of which seven cases were of PABC. Average age of presentation was 35 years. Most of the patients presented during lactation. It was found that most of the cases presented in advanced stage with large lump, involvement of skin and axillary lymph nodes. This was attributed to aggressive nature of these tumour, triple negative status on immunohistopathology, which was seen in all cases in our study and lack of awareness, un-education, low socioeconomic status and reluctance of patients to perform imaging or invasive procedures during pregnancy, precluding timely management. On USG larger lesion showed cystic changes and smaller lesions parallel orientation with posterior acoustic enhancement, mimicking benign lesion. Mammography act as complimentary imaging modality and MRI helps in better evaluation of disease extent and multi-centricity.

Conclusion: Incidence of PABC is increasing as more women are delaying child birth. USG is the imaging modality of choice for breast lumps presenting during pregnancy and lactation. Mammography act as a complimentary imaging modality. Imaging features of small lesions may mimic benign lesion, thus new palpable complex cystic masses or any mass persisting for more than two weeks during pregnancy and lactation warrant tissue sampling and should not be disregarded as a galactocele or an abscess. Most of the lesions are triple negative on immuno-histochemistry. Delay in diagnosis and aggressive nature of lesion attribute to most lesions presenting with large size, axillary lymph nodes and skin involvement. Thus, it is important to spread awareness of this entity and its radiological features, which will aid in its early diagnosis and management.

\section{INTRODUCTION}

$\mathrm{PABC}$ is defined as breast cancer that occurs during pregnancy or within the year following childbirth [1]. PABC is aggressive in nature and associated with poor prognosis. It is the most common malignancy occurring in pregnancy, having an incidence of 1 in 3000 to 1 in 10,000 pregnancies. Because of its aggressive nature it is the most common cause of cancer-related death in the pregnant and lactating patient [2,3]. Most common presentation of PABC, almost always is a palpable mass. Breast sonography is used as the initial imaging modality, however mammography act as a complementary imaging modality in these patients $[4,5]$. For prompt and accurate diagnosis, immediate image-guided biopsy of suspicious or indeterminate breast masses is necessary. Fine Needle Aspiration (FNA) during pregnancy may be associated with both increased false-positive and increased false-negative rates, thus ultrasound guided core biopsy is the accepted costeffective standard procedure for assessing breast masses during pregnancy and lactation [6].

The aim of our study was to evaluate the radiological features of pregnancy associated carcinoma and spread awareness of this entity, as knowledge of PABC will help in its early diagnosis and decrease mortality.

\section{MATERIALS AND METHODS}

This retrospective study was conducted in Integrated Breast Care Centre (IBCC) in All India Institute of Medical Sciences, Rishikesh, from $1^{\text {st }}$ January 2019 to $30^{\text {th }}$ June 2019. Pre designed proforma was used to collect all relevant information from the patients record, which included patient data, clinical and examination finding, provisional and final diagnosis. Brief history regarding any risk factors such as history of carcinoma breast/ovary/endometrium in patient or family and relation with patient, age of menarche, age of first child, number of children and total number of years of breast feeding, any exposure to radiation and hormone replacement therapy were taken as per hospital protocol.

All pregnant/lactating patients who present with breast lump are evaluated by USG (ultrasonography) and/or mammography and appropriate Breast Imaging Reporting and Data System (BIRADS) are assigned. In selected patients, where exact extension or multicentricity/multi-focality of the disease, need to be determined, 
Contrast-Enhanced Magnetic Resonance Imaging (CEMRI) breasts are also done, as it is a more sensitive modality. CEMRI is also imaging modality of choice in high risk patients, where USG and mammography do not show abnormality [7]. USG was performed on Mindray Z6, elastography was done on different USG machine (Logic S8), mammography on Hologic selenia G-XR-62728 and MRI on GE Discovery 750, 3 tesla machine.

\section{Inclusion Criteria}

All patients with BIRADS IV A, B, C or V lesion in breast presenting during pregnancy or lactation (within one year post pregnancy) who were proved to be malignant on histology.

\section{Exclusion Criteria}

Non pregnant/lactating patients were excluded from this study.

Patients with prior surgery in outside facility for the same complaint were excluded.

All imaging findings were recorded using standard BIRADS lexicon. BIRADS 4 and 5 lesions underwent histopathological examination after informed consent with standard aseptic precautions. In case of BIRADS 4 lesion, at first only USG guided FNAC was done, and if it showed suspicious, atypical cells or malignant features or was inconclusive, then USG guided biopsy was done. For BIRADS 5 lesion both USG guided FNAC and biopsy of the lesion and FNAC of the radiologically suspicious axillary lymph node was done. All the biopsy proven malignant lesions were included in the study. B Braun, 22 gauge sterile, single use needle was used for FNAC and 14 gauge automated $\operatorname{BARD}(\mathrm{R}) \mathrm{MAX}-\mathrm{CORE}(\mathrm{R})$ disposable core biopsy gun was used for biopsy. Radiological and Histopathological findings along with their respective management strategies are described in [Table/Fig-1-11].

\begin{tabular}{|c|c|c|c|}
\hline & USG findings & $\begin{array}{l}\text { Lymph nodal } \\
\text { status }\end{array}$ & $\begin{array}{l}\text { Elastography } \\
\text { strain ratio }\end{array}$ \\
\hline $\begin{array}{l}\text { Patient } 1 \\
\text { (31 years) }\end{array}$ & $\begin{array}{l}\text { Multi-focal irregular, multi- } \\
\text { lobulated, parallel, heterogenous } \\
\text { lesion showing Posterior Acoustic } \\
\text { Enhancement (PAE), in right } \\
\text { breast, in upper central and inner } \\
\text { quadrant, (12 to } 3 \text { o' clock), largest } \\
8 \times 7.5 \mathrm{~cm} \text {, showing cystic areas, } \\
\text { increased vascularity, skin and } \\
\text { muscle infiltration, nipple retraction. } \\
\text { [Table/Fig-5] }\end{array}$ & $\begin{array}{l}\text { infiltrated right } \\
\text { axillary lymph } \\
\text { nodes }\end{array}$ & 10 \\
\hline $\begin{array}{l}\text { Patient } 2 \\
\text { (36 years) }\end{array}$ & $\begin{array}{l}\text { Large irregular, micro-lobulated, } \\
\text { anti-parallel, heterogenous } \\
\text { lesion, in retro-areolar region, } \\
\text { involving all quadrants of right } \\
\text { breast } 10.2 \times 9.0 \mathrm{~cm} \text {, with PAE, } \\
\text { cystic areas, internal vascularity, } \\
\text { extensive skin thickening and } \\
\text { oedema and muscle infiltration } \\
\text { with retracted nipple }\end{array}$ & $\begin{array}{l}\text { infiltrated } \\
\text { bilateral axillary } \\
\text { and right } \\
\text { supra-clavicular } \\
\text { lymph nodes }\end{array}$ & 9 \\
\hline $\begin{array}{l}\text { Patient } 3 \\
\text { (38 years) }\end{array}$ & $\begin{array}{l}\text { Oval, multi-lobulated, parallel, } \\
\text { hypoechoic lesion showing PAE, } \\
\text { mild internal vascularity in right } \\
\text { breast in upper outer quadrant, at } \\
10 \text { o' clock } 2.5 \times 2.0 \mathrm{~cm} \text { in size. } \\
\text { [Table/Fig-9] }\end{array}$ & $\begin{array}{l}\text { infiltrated right } \\
\text { axillary lymph } \\
\text { nodes }\end{array}$ & $\begin{array}{c}4.8 \\
{[\text { Table/Fig-10] }}\end{array}$ \\
\hline $\begin{array}{l}\text { Patient } 4 \\
\text { (32 years) }\end{array}$ & $\begin{array}{l}\text { Irregular, micro-lobulated } \\
\text { heterogenous lesion, in retro- } \\
\text { areolar region, involving all } \\
\text { quadrants, measuring } 14 \times 12 \mathrm{~cm} \\
\text { showing PAE, cystic areas, } \\
\text { infiltrating in skin and muscle with } \\
\text { retracted nipple [Table/Fig-11] }\end{array}$ & $\begin{array}{l}\text { Right axillary } \\
\text { and supra- } \\
\text { clavicular } \\
\text { lymph node } \\
\text { involvement }\end{array}$ & 9 \\
\hline $\begin{array}{l}\text { Patient } 5 \\
\text { (29 years) }\end{array}$ & $\begin{array}{l}\text { Large, irregular, micro } \\
\text { lobulated, heterogenous lesion, } \\
\sim 8.2 \times 5.2 \mathrm{~cm} \text { in left breast, } \\
\text { predominantly in lower outer } \\
\text { quadrant and retroareolar location, } \\
\text { extending from } 8 \text { to } 4 \text { o'clock } \\
\text { position, showing PAE, cystic } \\
\text { areas, infiltrating in skin and } \\
\text { muscle with nipple retraction. }\end{array}$ & $\begin{array}{l}\text { infiltrated left } \\
\text { axillary and } \\
\text { supra-clavicular } \\
\text { lymph nodes }\end{array}$ & 9 \\
\hline
\end{tabular}

\begin{tabular}{|l|l|l|c|}
\hline $\begin{array}{l}\text { Patient 6 } \\
\text { (41 years) }\end{array}$ & $\begin{array}{l}\text { Micro-lobulated hypoechoic, } \\
\text { parallel lesion, showing PAE, } \\
2.7 \times 2.2 \mathrm{~cm} \text { in right breast } \\
\text { in upper outer quadrant, at } \\
10 \text { o'clock position, showing } \\
\text { mild internal vascularity. }\end{array}$ & $\begin{array}{l}\text { no lymph node } \\
\text { infiltration }\end{array}$ & 5 \\
\hline $\begin{array}{l}\text { Patient } 7 \\
\text { (35 years) }\end{array}$ & $\begin{array}{l}\text { Micro-lobulated hypoechoic, } \\
\text { parallel, lesion with posterior } \\
\text { acoustic enhancement, mild } \\
\text { internal vascularity, } 2.2 \times 2.1 \mathrm{~cm} \\
\text { in right breast in upper inner } \\
\text { quadrant at 1 o'clock position }\end{array}$ & $\begin{array}{l}\text { infiltrated right } \\
\text { axillary lymph } \\
\text { nodes }\end{array}$ & 6 \\
[Table/Fig-1]: USG findings. & & \\
\hline
\end{tabular}

Mammography findings

\begin{tabular}{|c|c|}
\hline & Mammography findings \\
\hline Patient 1 & $\begin{array}{l}\text { Multifocal microlobulated, high density lesions in right breast, in upper inner } \\
\text { and central quadrant (12-3 o' clock position) with surrounding architectural } \\
\text { distortion, measuring } 9 \times 8.5 \mathrm{~cm} \text { infiltrating in skin and pectoralis muscles, } \\
\text { retracted nipple, no micro-calcification seen [Table/Fig-4,6] }\end{array}$ \\
\hline Patient 2 & $\begin{array}{l}\text { Irregular microlobulated and spiculated, high density lesion in right } \\
\text { breast, in retro-areolar region involving all quadrants, measuring } \\
10.8 \times 9.5 \mathrm{~cm} \text {, with surrounding architectural distortion showing } \\
\text { clustered pleomorphic micro-calcifications, extensive skin thickening with } \\
\text { odema, infiltrating in pectoralis muscle, with retracted nipple [Table/Fig-8] }\end{array}$ \\
\hline Patient 3 & $\begin{array}{l}\text { Well-defined, lobulated iso-high density lesion without microcalcifications } \\
\text { in right breast, in upper outer quadrant at } 10 \text { o' clock, measuring } \\
2.5 \times 1.8 \mathrm{~cm} \text {. }\end{array}$ \\
\hline Patient 4 & $\begin{array}{l}\text { Irregular micro-lobulated high density lesion in right breast, with } \\
\text { surrounding architectural distortion showing clustered pleomorphic micro- } \\
\text { calcifications, infiltrating in skin and pectoralis muscle, with retracted nipple } \\
\text { in retro-areolar region, involving all quadrants, measuring } 14.2 \times 13 \mathrm{~cm}\end{array}$ \\
\hline Patient 5 & $\begin{array}{l}\text { Large, micro-lobulated, high density lesion with pleomorphic micro } \\
\text { calcifications, surrounding architectural distortion, } \sim 9.6 \times 5.8 \mathrm{~cm} \text {, } \\
\text { infiltrating in skin and pectoralis muscle, retracted nipple in left breast, } \\
\text { predominantly in lower outer and central quadrant. }\end{array}$ \\
\hline Patient 6 & $\begin{array}{l}\text { A micro-lobulated, high density lesion, with no micro-calcification } \\
\sim 2.9 \times 2.2 \mathrm{~cm} \text { in upper outer quadrant, at } 10 \text { o'clock position of } \\
\text { right breast }\end{array}$ \\
\hline Patient 7 & $\begin{array}{l}\text { Micro-lobulated, high density lesion of size } 2.5 \times 2.4 \mathrm{~cm} \text { showing foci } \\
\text { of clustered pleomorphic micro-calcification in upper inner quadrant at } \\
1 \text { o'clock position of right breast. }\end{array}$ \\
\hline
\end{tabular}

\begin{tabular}{|c|c|}
\hline & Management \\
\hline Patient 1 & $\begin{array}{l}4 \text { cycles of neo-adjuvant chemotherapy, which included } \\
\text { Cyclophosphamide } 600 \mathrm{mg} / \mathrm{m}^{2} \text { and Doxorubicin } 60 \mathrm{mg} / \mathrm{m}^{2} \text { after which } \\
\text { a repeat mammogram was done for response assessment. Four more } \\
\text { cycles of neo-adjuvant chemotherapy, was given as tumour showed } \\
\text { less response. Followed by repeat mammogram, which showed } \\
\text { partial response. Followed by modified radical mastectomy and } \\
\text { radiotherapy. }\end{array}$ \\
\hline Patient 2 & $\begin{array}{l}4 \text { cycles of neo-adjuvant chemotherapy, which included } \\
\text { Cyclophosphamide } 600 \mathrm{mg} / \mathrm{m}^{2} \text { and Doxorubicin } 60 \mathrm{mg} / \mathrm{m}^{2} \text { after which } \\
\text { a repeat mammogram was done for response assessment. Four more } \\
\text { cycles of neo-adjuvant chemotherapy, was given as tumour showed } \\
\text { less response. Followed by repeat mammogram, which showed partial } \\
\text { response. Followed by modified radical mastectomy and radiotherapy. }\end{array}$ \\
\hline Patient 3 & $\begin{array}{l}\text { Breast conservative surgery, followed by chemotherapy and } \\
\text { radiotherapy }\end{array}$ \\
\hline Patient 4 & $\begin{array}{l}4 \text { cycles of neo-adjuvant chemotherapy, which included } \\
\text { Cyclophosphamide } 600 \mathrm{mg} / \mathrm{m}^{2} \text { and Doxorubicin } 60 \mathrm{mg} / \mathrm{m}^{2} \text { after which } \\
\text { a repeat mammogram was done for response assessment. Four more } \\
\text { cycles of neo-adjuvant chemotherapy, was given as tumour showed } \\
\text { less response. Followed by repeat mammogram, which showed partial } \\
\text { response. Followed by modified radical mastectomy and radiotherapy. }\end{array}$ \\
\hline Patient 5 & $\begin{array}{l}4 \text { cycles of neo-adjuvant chemotherapy, which included } \\
\text { Cyclophosphamide } 600 \mathrm{mg} / \mathrm{m}^{2} \text { and Doxorubicin } 60 \mathrm{mg} / \mathrm{m}^{2} \text { after which } \\
\text { a repeat mammogram was done for response assessment. } 4 \text { more } \\
\text { cycles of neo-adjuvant chemotherapy, was given as tumour showed } \\
\text { less response. Followed by repeat mammogram, which showed partial } \\
\text { response. Followed by modified radical mastectomy and radiotherapy. }\end{array}$ \\
\hline Patient 6 & Breast conservative surgery, followed by chemotherapy and radiotherapy. \\
\hline Patient 7 & Breast conservative surgery, followed by chemotherapy and radiotherapy. \\
\hline
\end{tabular}

Statistical calculations were done using simple percentage. Tables of the data were prepared as excel sheets. 


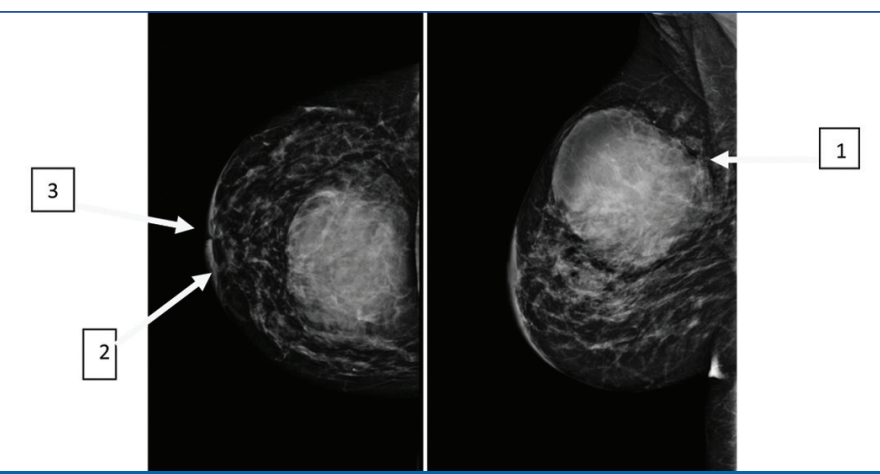

[Table/Fig-4]: Patient 1, 31-year-old female, para 1, presented with lump of 4 month duration during lactation (6 months post partum). On mammogram large micro-lobulated mass, with surrounding architectural distortion, indistinct fat planes with underlying pectoralis muscle (arrow 1) and peri-areolar skin thickening (arrow 2) was seen in right breast. Nipple is fixed (arrow 3). No micro-calcification seen.

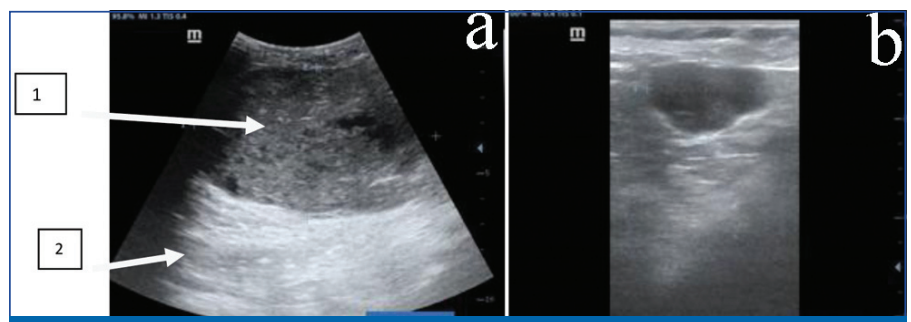

[Table/Fig-5]: a) Corresponding USG of the above patient, shows a large mass with anechoic cystic/necrotic areas (arrow 1) and posterior acoustic enhancement, (arrow 2) a feature characteristically seen in triple negative patients. b) Shows enlarged lobulated infiltrated ipsilateral axilary lymph nodes with loss of hila.

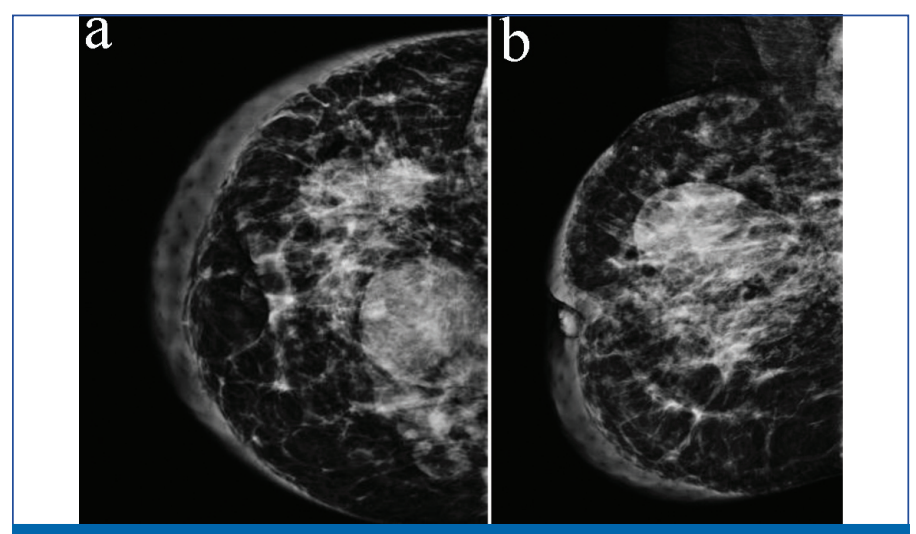

[Table/Fig-6]: Repeat mammogram of patient 1, after 8 cycles of chemotherapy shows decrease in size of tumour, suggesting partial response.

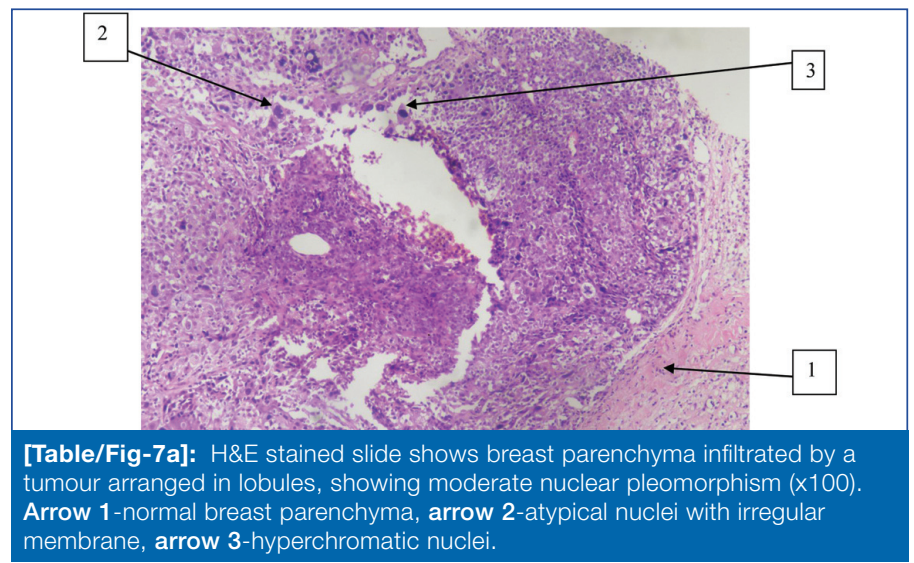

\section{RESULTS}

\section{- Incidence}

From $1^{\text {st }}$ January 2019 to $30^{\text {th }}$ June 2019,196 cases of carcinoma breast came in integrated breast care centre, 37 patients presented with BIRADS IV or $\mathrm{V}$ lesion during pregnancy or lactation, out of which seven proved to be malignant on USG guided trucut biopsy. Hence the incidence of PABC among malignant cases was $3.5 \%$.

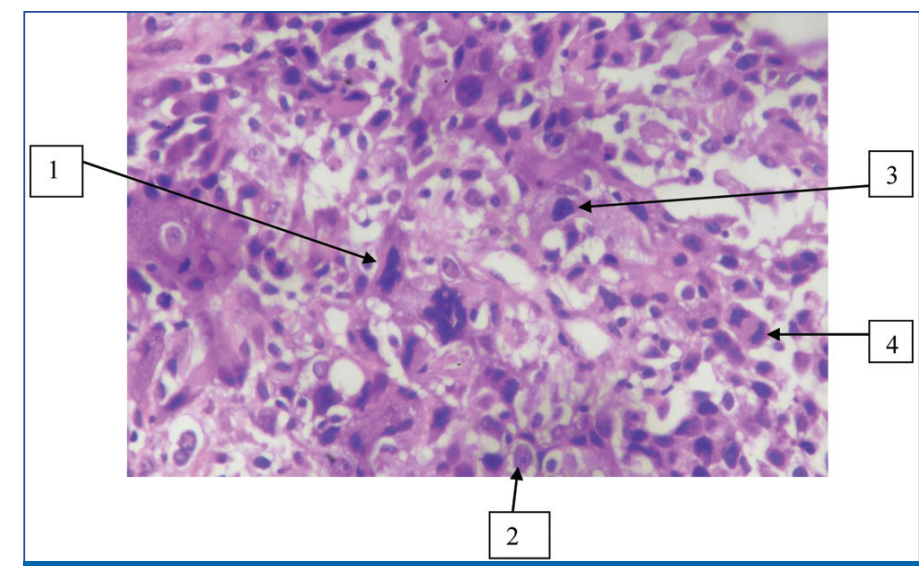

[Table/Fig-7b]: H\&E stained slide $(x 400)$ shows tumour cells, showing moderate nuclear pleomorphism (arrow 1), conspicuous nucleoli (arrow 2), irregular nuclear membranes, hyperchromatic nucleus (arrow 3), occasional mitotic figures (arrow 4)

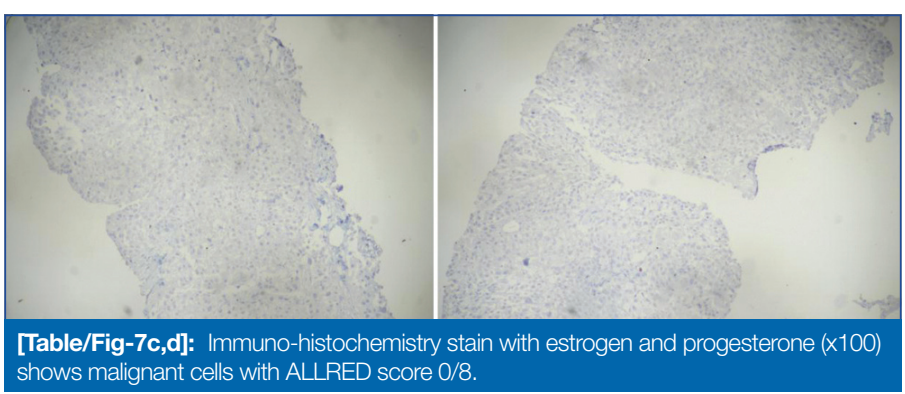

shows malignant cells with ALLRED score $0 / 8$.
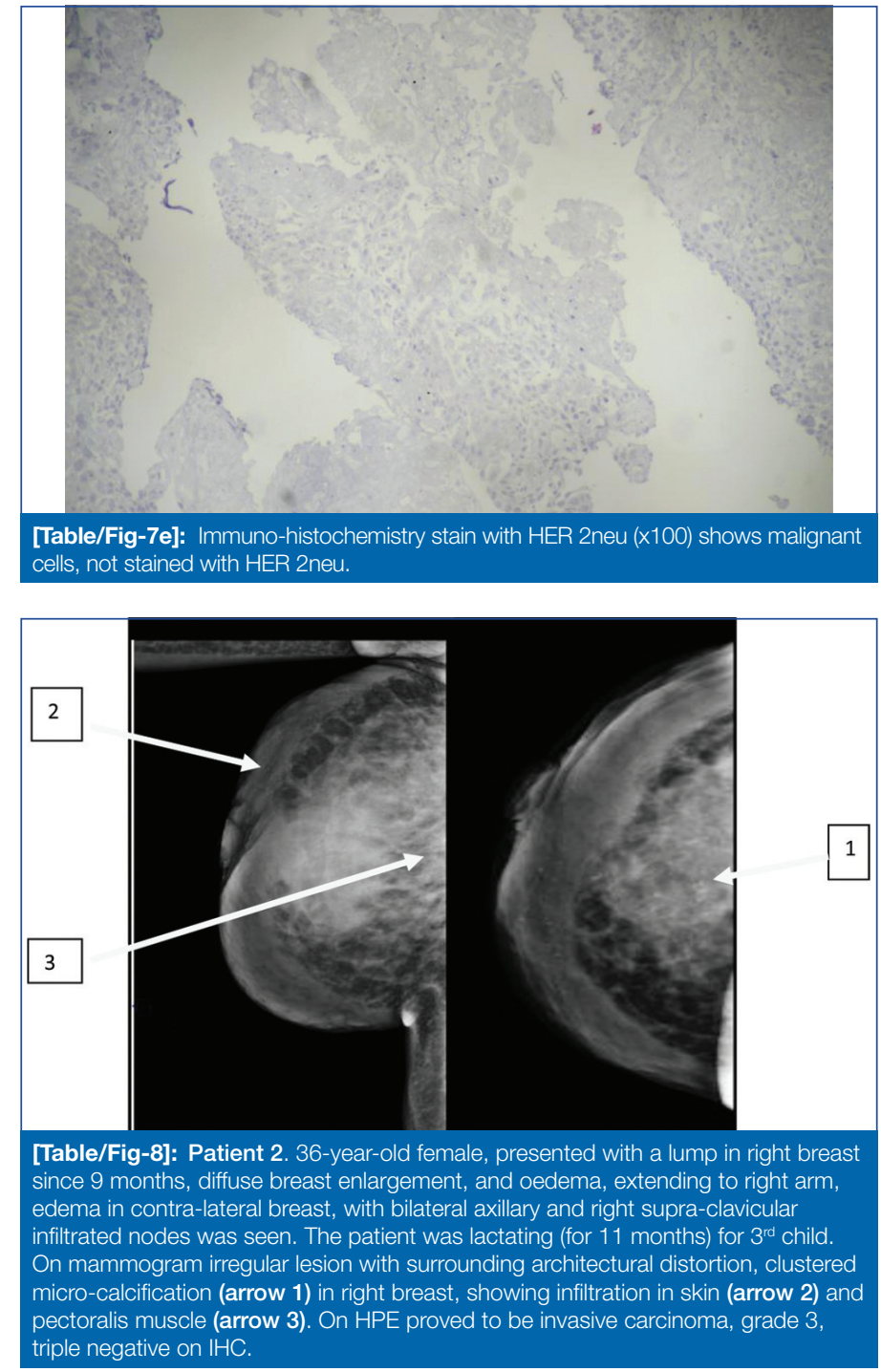

\section{- Demographic Features}

Average age of presentation was 35 years, ranging from 29 to 41 years. The socio-economic status of all patients belonged to IV 


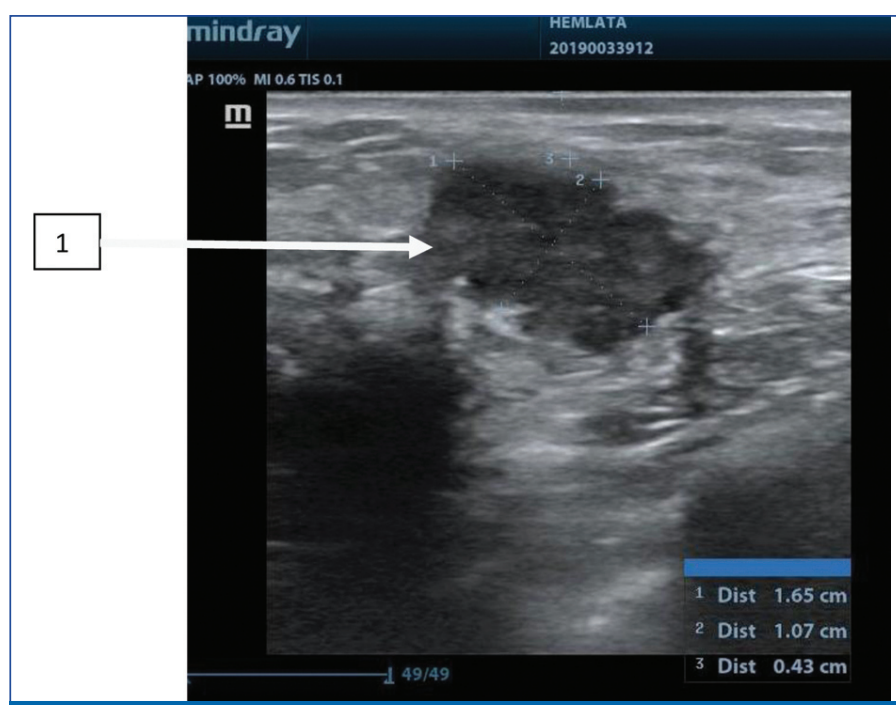

[Table/Fig-9]: Patient 3- 38-year-old female, who had history of abortion 4 months back, (intra-uterine foetus was of 10 week-21/2 months), presented with lump in right breast since 5 months, one month after pregnancy. History of pre-menopausa carcinoma breast was present in mother. On USG a micro-lobulated hypoechoic wider than tall lesion (arrow 1) was seen in right breast, showing posterior acoustic enhancement, characteristic of triple negative carcinoma. On HPE proved to be invasive carcinoma grade 2 , triple negative on $\mathrm{HC}$

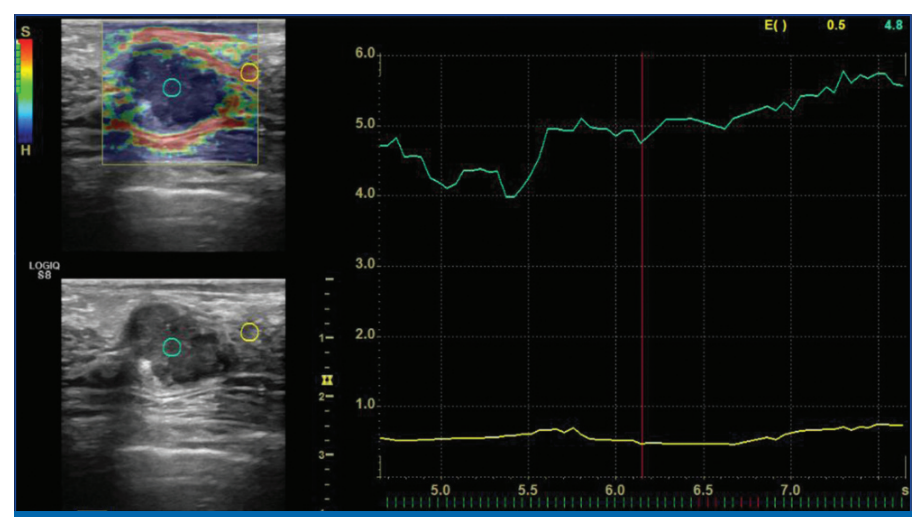

[Table/Fig-10]: Elastography of the lesion in patient 3, shows strain ratio of 4.8, which in suggestive of malignant lesion.
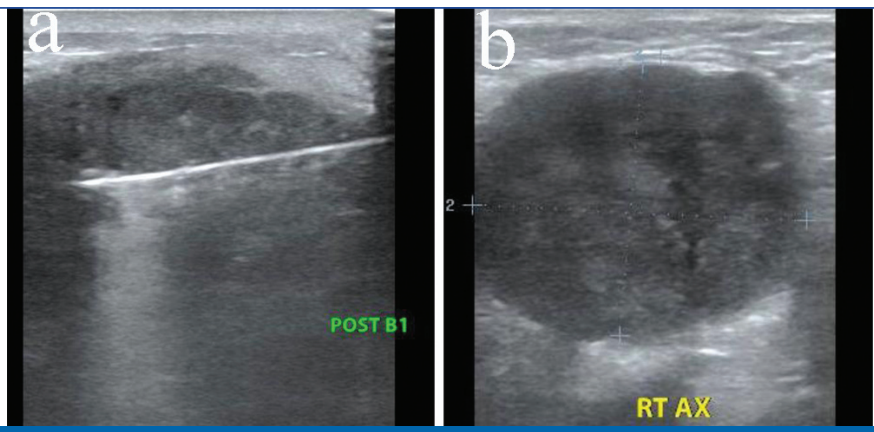

[Table/Fig-11]: Patient 4- 32-year-old primi gravida presented with lump in right breast since 9 months. Patient was nursing and had delivered 11 months before a) USG of right breast shows a large lobulated heterogeneously hypoechoic mass, with anechoic cystic / necrotic areas and internal vascularity. b) Showed lobulated hypoechoic axillary lymph node with posterior acoustic enhancement. On HPE proved to be triple negative, poorly differentiated invasive carcinoma.

and $V$ category according to modified BG Prasad's classification, 2016 (low socio-economic status) [8]. Six patients were illiterate and one patient was educated up to $5^{\text {th }}$ class.

\section{- Association with Risk Factors}

Out of the seven patients, one patient had a history of premenopausal carcinoma breast in mother (14\%) and three patients had first child birth, after the age of 30 (42\%).

\section{- Time of Presentation}

Two patients (28.5\%) presented during pregnancy and 5 (71.1\%) during lactation. All (100\%) patients presenting during lactation, presented within six months of delivery.

\section{- Clinical Presentation}

Clinical complaints and signs present in these patients were lump (100\%), diffuse enlargement of breast with skin thickening (4 patients, 57.5\%), fixed or retracted nipple (4 patients, 57.5\%), and nipple discharge (3 patients, 42.8\%). Axillary lymph node involvement was seen in six patients (85.7\%), one patient presented with bilateral axillary lymph node involvement (14\%). Multi-centric lesion was seen in 1 patient (14\%). Size of the lump at presentation varied from 2.5 to $14 \mathrm{~cm}$, in greatest dimension, with average size being $8.2 \mathrm{~cm}$.

\section{- USG Findings}

USG findings of patients are elaborated in [Table/Fig-1].

\section{- Mammographic Findings}

Mammographic findings of patients are elaborated in [Table/Fig-2].

\section{- MRI Findings}

MRI was done in one patient, who presented with lump during lactation, showing multifocal extension on USG, for adequate assessment of extent of disease and evaluation of contra-lateral breast. Before the scan the patient was asked to express milk from both breasts. After completion of scan the patient was asked to express and discard milk for 24 hours, as very small amount of $\mathrm{MRl}$ contrast is excreted in breast milk. More lesions were picked up in MRI as compared to USG and mammography, some of which were seen more than $4 \mathrm{~cm}$ away from each other, and in different quadrants, determining the multi-centricity of lesion, hence proving as a better modality in determining extent of disease and multicentricity of the disease.

\section{- Histopathological Finding}

In case of BIRADS 4 lesion, at first only USG guided FNAC was done, and if it showed suspicious, atypical cells or malignant features or was inconclusive, then USG guided biopsy was done. For BIRADS 5 lesion both USG guided FNAC and biopsy of the lesion and FNAC of the radiologically suspicious axillary lymph node was done. Before performing the procedure, the reason for doing, procedure details, risk of complications, utility were explained to patient and informed consent was taken. Patient was asked to stop breast feeding, a day before doing the procedure and strict asepsis was maintained during the procedure. On histopathology all cases were diagnosed as invasive ductal carcinoma, 5 of grade 3 and 2 of grade 2. On immuno-histochemistry, all cases (100\%) were triple negative (ER, PR and HER-2 negative) [Table/Fig-7]

\section{- Management}

All patients diagnosed with PABC were managed in IBCC after discussion in multidisciplinary tumour board by surgeon, radiologist, radiotherapist and medical oncologist at the IBCC [Table/Fig-3].

\section{DISCUSSION}

$\mathrm{PABC}$ is rare, having an incidence of approximately $0.3 / 1000$ pregnancies. Though it represents only $0.2-3.8 \%$ of all newly diagnosed breast cancer, it constitute $10 \%$ of newly diagnosed breast cancer cases in women younger than 40 years [6]. Similar findings were also seen in our study where it represented $3.5 \%$ of all malignant cases encountered during our study period and $15 \%$ of malignancy in women less than 40 years.

Average age of presentation of PABC in our study was 35 years, ranging from 28 to 41 years. This was comparable with the study by Langer $A$ et al., and Vashi $R$ et al., who stated the average age of presentation of PABC to be between 32 and 34 years $[1,6]$.

There are various risk factors associated with PABC. Hou $N$ et al., in their study stated family history, genetic mutation (BRCA 1 and 2 genes) and advanced age of first pregnancy as few of the risk factors 
associated with pregnancy associated breast carcinoma [9]. Study by Barnes DM and Newman LA, also stated that women with their first pregnancy after the age of 30 years are two to three times more likely to be diagnosed with breast cancer than women with their first pregnancy before the age of 30 years [10]. In our study advanced age of first child birth was seen in 3 cases (42.8\%) and family history of pre-menopausal carcinoma breast in 1 patient (14\%).

Most of the patients of PABC presented in our study during lactation, with majority presenting within six months of delivery. This is comparable with the study of Ayyappan A et al., which states that around two-thirds of all PABC cases are diagnosed in the postpartum period, mostly in the first six months following delivery [11]. The average time from onset of symptom to diagnosis in these patients was five months, this was compatible with study by Woo JC et al., [12].

Most common presentation in patients with PABC, almost always is a palpable mass [12]. This was the most common presentation in our study as well with all cases presenting with breast lump. Most of the lesions were large at the time of presentation, showed skin infiltration, involvement of axillary lymph nodes, and one with multicentric extension, suggesting aggressive nature of the lesion. The size of lesion in our study ranged from 2.5 to $14 \mathrm{~cm}$, in greatest dimension, with average being $8.2 \mathrm{~cm}$. Large size of the lesion was also attributed to delay in diagnosis, due to patient's lack of awareness, education and low socio-economic status, leading to delay in coming to the hospital. This finding was comparable with the study by $\mathrm{Yu} J$ et al., who stated that these lesions are aggressive in nature and present in an advanced stage at the time of diagnosis [13].

During pregnancy and lactation, the hormonal changes make clinical and radiologic evaluations of the breast difficult. Despite generalised nodularity of the breast on physical examination during pregnancy and lactation, all patients with a dominant palpable breast mass that persists for two weeks or longer should be evaluated with a targeted ultrasound examination. Sensitivity of sonography in the diagnosis of PABC is 100\% [4]. USG helps in differentiating benign from malignant breast masses. Physiological changes associated with the breast and lactation may alter typical sonographic features of breast carcinoma. Parallel orientation to skin and posterior acoustic enhancement commonly seen in benign breast lesions has been reported in 58\% and $63 \%$ of PABC cases respectively in study by Loibl S et al., [14]. Similarly in our study USG was used as the first imaging modality. All cases (100\%) showed posterior acoustic enhancement, a property commonly seen in benign breast lesions. This finding was also attributed to the fact that most PABC are triple negative on immune-histochemistry, and triple negative tumous characteristically show posterior acoustic enhancement [15]. All small sized lesions showed parallel orientation with welldefined margins. These findings were also seen in study performed by Ahn BY et al., [16].

Since small sized lesion mimicked benign lesion, elastography was used to further assess these lesions. It was found that all lesions whether small or large showed higher strain ratio (greater than 4), indicating there malignant nature and thus aiding in diagnosis. Schnitt SJ and Guidi AJ, found that when a cut-off point of between 3 and 4 was used, for malignant lesions, elastography had $86.5 \%$ sensitivity, $89.8 \%$ specificity, and $88.3 \%$ accuracy [17]. Thus using this cut-off, all lesions showed strain ratio of malignant lesion in our study.

Since PABCs are aggressive neoplasm, they may outgrow their vascular supply causing necrosis or cystic degeneration [12]. In our study all large sized lesions showed cystic degeneration/necrosis. Therefore, all new palpable masses identified during pregnancy and lactation showing complex cystic appearance, need tissue sampling and should not be disregarded as an abscess or a galactocele [11].
Despite dense breast parenchyma, the sensitivity of mammography in diagnosing PABC is 78-90\% [18]. In our study irregular high density lesion with architectural distortion, skin thickening and pectoralis muscle infiltration were seen in majority of the cases, on mammography. Micro-calcifications may or may not be present. It was seen in four of our cases (57\%). Similar findings were also seen in study performed by Yang WT et al., [18].

The MRI features of PABC include mass with rim enhancement, homogeneously and heterogeneously enhancing masses, nonmass segmental enhancement and diffuse unilateral enhancement, these are similar to those of non-PABC cases. As compared to lactating tissue, PABCs demonstrate a faster and greater degree of enhancement, helping in identification of these lesions [11]. In our study MRI was done in one patient, who presented with lump during lactation, showing multifocal extension on USG, for adequate assessment of extent of disease and evaluation of contralateral breast. More lesions were picked up in MRI as compared to USG and mammography, some of which were seen more than $4 \mathrm{~cm}$ away from each other, and in different quadrants, determining the multi-centricity of lesion, hence proving as a better modality in determining extent of disease and multicentricity of the disease. The utility of MRI in better depiction of disease extent and determining multi-centricity has also been reported in studies by Espinosa LA et al., and Talele AC et al., [19,20].

In our study proper instructions were given to the patient before start of procedure and strict asepsis was maintained. No immediate complications of trucut biopsy were seen.

Historically, these cancers are associated with a poor prognosis and advanced stage, likely secondary to a delay in diagnosis [21]. The most common histopathology and immunohistochemistry features of pregnancy associated breast cancer have been reported as high-grade invasive ductal carcinoma that is oestrogen receptornegative and progesterone receptor-negative with a high rate of lymphovascular invasion [22]. Similar findings were also seen in our study where all cases were diagnosed as invasive ductal carcinoma, 5 of grade 3 and 2 of grade 2 . On immune-histochemistry all cases (100\%) were triple negative (ER, PR and HER-2 negative). Thus most of the tumours were of high grade and triple negative type, having poor prognosis a finding commonly seen in PABC.

It is important not to delay treatment, once a diagnosis of breast cancer has been made. However if the patient is near term, treatment can be delayed till delivery. If the patient is remote from term, treatment must be initiated. There has been no evidence to show that the prognosis is affected by termination of pregnancy in the first or second trimester [22].

For PABC, surgery is the first line of treatment. Modified radical mastectomy being the treatment of choice for operable disease. During pregnancy radiation therapy is contraindicated, due to an increased risk of fetal malformations and delays in neurocognitive development. Though mastectomy is the first line of treatment, breast-conserving surgery and radiation can be done in pregnant patients who present with breast cancer near term, after their delivery [23]. In our study one patient presented with lump during pregnancy, but had aborted (10 weeks of gestation) spontaneously 4 months before coming to breast clinic, hence she was managed by breast conservative surgery, followed by chemotherapy and radiotherapy. The other patients having large lesion were managed by giving chemotherapy, and planned for modified radical mastectomy and radiotherapy.

\section{LIMITATION}

There were some limitations in our study, which included small study sample size, follow-up of patients only 3-6 months and unavailability of BRCA 1 and 2 gene screening. 


\section{CONCLUSION}

Increased density and physiological changes in breast during pregnancy and lactation, together with unawareness of the entity, leads to delay in diagnosis with presentation of PABC in advanced stage. Ultrasound is the initial imaging of choice, however mammography act as a complementary test as it detects otherwise occult malignant microcalcifications. Features like posterior acoustic enhancement and cystic degeneration are highly suggestive of PABC, however more studies with larger sample size should be done to confirm this finding.

\section{REFERENCES}

[1] Langer A, Mohallem M, Berment H, Ferreira F, Gog A, Khalifa D, et al. Breast lumps in pregnant women. Diagnostic and Interventional Imaging. 2015;96(10):1077-87.

[2] Gemignani ML, Petrek JA. Pregnancy-associated breast cancer: Diagnosis and treatment. Breast J. 2000;6:68-73.

[3] Hogge JP, De Paredes ES, Magnant CM, Lage J. Imaging and management of breast masses during pregnancy and lactation. Breast J. 1999;5:272-83.

[4] Sabate JM, Clotet M, Torrubia S, Gomez A, Guerrero R, de las Heras P, et al. Radiological evaluation of breast disorders related to pregnancy and lactation. Radiographics. 2007;27:S101-24.

[5] Woitek R, Prayer D, Hojreh A, Helbich T. Radiological staging in pregnant patients with cancer. ESMO Open. 2016;1(1);000017.

[6] Vashi R, Hooley, R., Butler, R., Geisel, J. and Philpotts, L. Breast limaging of the pregnant and lactating patient: Imaging modalities and pregnancy-associated breast cancer. American Journal of Roentgenology, 2013;200(2): 321-28.

[7] Wellings E, Vassiliades L, Abdalla R. Breast cancer screening for high-risk patients of different ages and risk- which modality is most effective? Cureus. 2016;8(12):e945.

[8] Khairnar MR, Wadgave U, Shimpi PV. Updated BG Prasad socioeconomic classification for 2016. J Indian Assoc Public Health Dent. 2016;14:469-70.
[9] Hou N, Ogundiran T, Ojengbede O, Morhason-Bello IO, Zheng Y, Fackenthal $\mathrm{J}$, et al. Risk factors for pregnancy-associated breast cancer: A report from the Nigerian Breast Cancer Study. Annals of Epidemiology. 2013;23(9):551-57.

[10] Barnes DM, Newman LA. Pregnancy-associated breast cancer: A literature review. Surg Clin North Am. 2007; 87:417-30, x.

[11] Ayyappan A, Kulkarni S, Crystal P. Pregnancy-associated breast cancer: Spectrum of imaging appearances. The British Journal of Radiology. 2010;83(990):529-34.

[12] Woo JC, Yu T, Hurd TC. Breast cancer in pregnancy: A literature review. Arch Surg. 2003;138:91-98; discussion, 99.

[13] Yu J, Kim M, Cho H, Liu H, Han S, Ahn T. Breast diseases during pregnancy and lactation. Obstetrics \& Gynecology Science. 2013; 56(3): 143.

[14] Loibl S, von Minckwitz G, Gwyn K, Ellis P, Blohmer JU, Schlegelberger B, et al. Breast carcinoma during pregnancy. Cancer. 2006; 106: 237-46.

[15] Kawashima $\mathrm{H}$. Imaging findings of triple-negative breast cancer. Breast Cancer. 2010;18(3):145

[16] Ahn BY, Kim HH, Moon WK, Pisano ED, Kim HS, Cha ES, et al. Pregnancy- and lactation-associated breast cancer: Mammographic and sonographic findings. J Ultrasound Med. 2003;22:491-97.

[17] Schnitt SJ, Guidi AJ. Pathology of invasive breast cancer. In diseases of the breast. Harris JR, Lipmann ME, Morrow M, Osborne CK. $3^{\text {rd }}$ edition, Lippincott, William and Wilkins. Philadelphia. 2004. 393.

[18] Yang WT, Dryden MJ, Gwyn K, Whitman GJ, Theriault R. Imaging of breast cancer diagnosed and treated with chemotherapy during pregnancy. Radiology. 2006; 239:52-60.

[19] Espinosa LA, Daniel BL, Vidarsson L, Zakhour M, Ikeda DM, Herfkens RJ. The lactating breast: Contrast-enhanced MR imaging of normal tissue and cancer. Radiology. 2005;237:429-36.

[20] Talele AC, Slanetz PJ, Edmister WB, Yeh ED, Kopans DB. The lactating breast: MRI findings and literature review. Breast J. 2003;9:237-40.

[21] Tirada N, Dreizin D, Khati N, Akin E, Zeman R. Imaging pregnant and lactating patients. Radiographics. 2015;35(6):1751-65.

[22] Lenhard MS, Bauerfeind I, Untch M. Breast cancer and pregnancy: Challenges of chemotherapy. Crit Rev Oncol Hematol. 2008;67:196-203.

[23] Molckovsky A, Madarnas Y. Breast cancer in pregnancy: A literature review. Breast Cancer Res Treat. 2008;108:333-38.

\footnotetext{
PARTICULARS OF CONTRIBUTORS:

1. Senior Resident, Department of Integrated Breast Care Centre (IBCC), All India Institute of Medical Sciences (AllMS), Rishikesh, Uttarakhand, India.

2. Additional Professor, Department of Integrated Breast Care Centre (IBCC), All India Institute of Medical Sciences (AllMS), Rishikesh, Uttarakhand, India.

3. Senior Professor, Department of Integrated Breast Care Centre (IBCC), All India Institute of Medical Sciences (AllMS), Rishikesh, Uttarakhand, India.

4. Professor, Department of Integrated Breast Care Centre (IBCC), All India Institute of Medical Sciences (AllMS), Rishikesh, Uttarakhand, India.

5. Professor, Department of Integrated Breast Care Centre (IBCC), All India Institute of Medical Sciences (AllMS), Rishikesh, Uttarakhand, India.

6. Senior Resident, Department of Integrated Breast Care Centre (IBCC), All India Institute of Medical Sciences (AllMS), Rishikesh, Uttarakhand, India.

7. Senior Resident, Department of Integrated Breast Care Centre (IBCC), All India Institute of Medical Sciences (AlIMS), Rishikesh, Uttarakhand, India.

8. Senior Resident, Department of Integrated Breast Care Centre (IBCC), All India Institute of Medical Sciences (AlIMS), Rishikesh, Uttarakhand, India.
}

NAME, ADDRESS, E-MAIL ID OF THE CORRESPONDING AUTHOR:

Dr. Aakriti Kapoor,

House Number 111, P.O S.N. Temple, Shyampur, Rishikesh-249204, Uttarakhand, India

E-mail: aakritikapoor911989@gmail.com

Date of Submission: Jul 17, 2019

Date of Peer Review: Jul 31, 2019

Date of Acceptance: Sep 30, 2019

FINANCIAL OR OTHER COMPETING INTERESTS: None. 